\title{
A Maquiagem e o Rosto sob a Máscara da Commedia dell'Arte
}

\author{
The dialogical teacher: some practical \\ proposals for the theatre workshop
}

\author{
por Claudia Contin \\ tradução de Aline Castaman
}

\section{RESUMO}

A escolha destes dois objetos de estudo para tradução, referentes à maquiagem e ao rosto sob a máscara na Commedia dell'Arte a partir do livro escrito por Claudia Contin, está relacionada ao trabalho apurado e significativo a respeito da arte do ator feito pela atriz que atende pelo nome de Arlecchino. Sua escritura possibilita ao aluno-ator ter acesso às singularidades do vestir a máscara e tudo que gira em torno dessa particularidade. De um rosto que, independente de estar sob a máscara, também exige uma musculatura tão afinada quanto o treinamento voltado para o corpo e suas extremidades. Claudia sublinha a importância da maquiagem sob a máscara para que o efeito daquele que a veste seja bem sucedido. A ideia de traduzir estes dois capítulos é de apresentar apenas um pouco da complexidade do treinamento envolvido nessa arte em especial e do qual a tradutora pode experimentar através de um curso ministrado por Claudia em setembro de 2010 na Itália.

Palavras-chave Commedia dell’Arte; maquiagem; rosto; máscara

\section{ABSTRACT}

The choice of these two objects of studying for translation, which refer to the make-up and the face under the mask in Commedia dell'Arte from the book written by Claudia Contin, is related to the very fine and significant work on the actor's art done by her who attends by the name Arlecchino. Her writing allows the student-actor to have access to the singularities of wearing a mask and everything that revolves around it. A face that, regardless being under the mask also requires a musculature so turned up as the training focused on the body and its extremities. Claudia stresses the importance of the make-up to the effect of whom wears the mask to be well successful. The idea of translating these two chapters infers a little about the complexity of the training involved in this art in particular and which the translator could experience through a course ministered by Claudia in September 2010 in Italy.

Keywords Commedia dell'Arte; make-up; face; mask 


\section{Cena Quinze - A Maquiagem Sob A Máscara}

E agora, tendo revelado todos os segredos das máscaras físicas do corpo do ator, o mestre pode finalmente colocar a máscara de couro nas mãos do estudante. A máscara de couro é um objeto muito especial, símbolo e coroamento de um longo processo de mascaramento profundo que 0 ator experiencia durante este aprendizado em particular: o momento em que chegamos a colocar a máscara corresponde ao último empurrão para um salto de identidade para o qual há muito tempo o aluno tem se preparado. É por esse motivo que a relação entre o ator e a máscara é cheia de pequenos e preciosos rituais que, mesmo quando transpostos para o mundo grotesco da Commedia dell' Arte, correspondem aos ritos de "vestir" de um cavaleiro que está prestes a ir para a batalha. Alguns desses ritos têm sido reunidos, selecionados e recontextualizados dentro dos cursos pedagógicos sobre a Commedia dell' Arte que têm sido sistematizados pela Scuola Sperimentale dell' Attore.

Um dos ritos fundamentais para garantir o distanciamento necessário é a chamada "maquiagem sob a máscara". Qual o propósito de maquiar o rosto que logo será coberto pela máscara? Como todo rito que se preza, mesmo a maquiagem sob a máscara tem razões supersticiosas por um lado e razões extremamente práticas e funcionais por outro.

(0 ator pega os materiais do estojo de maquiagem e pouco a pouco começa a maquiar o rosto enquanto continua a explicação.)

Essas máscaras usadas na Commedia dell' Arte não são pintadas como muita máscaras de origem Oriental; e elas não têm uma expressão predeterminada fixada pelos tons das cores. As máscaras da Commedia dell' Arte são esculturais o invés de pintadas. Suas linhas não são exclusivamente tristes ou exclusivamente alegres, nem mesmo determinadas psicologicamente. A Personagem que é esculpida em linhas grotescas no couro é pré-expressiva e, portanto, antecedente a qualquer que seja "o motivo psicológico expressivo" da personagem.

A expressividade delas aumenta na medida em que elas são postas em movimento: se as viramos para baixo elas parecem expressar tristeza; se as direcionamos para cima elas parecem gargalhar; se as viramos um pouco para o lado elas parecem expressar dúvida. Para resumir, elas "ganham vida" quando reagem ao movimento e à luz.

As aberturas que elas têm para os olhos são relativamente grandes se comparadas às de outras máscaras que possuem buracos menores ou uma fissura pouco aberta. Isso se deve ao fato de a Commedia dell' Arte ser um tipo de teatro bastante acrobático que apresenta movimentos amplos, e por isso, o ator precisa ter uma amplitude de visão que o permita agir em cena. Além disso, a luminosidade do olho humano, quando se faz visível, destaca-se de forma particularmente vivaz no 'focinho" escuro da máscara. Assim, a maquiagem castanho escura é utilizada, da mesma tonalidade

1 Muzzle. 
da máscara que queremos vestir, para pintar toda a região ao redor do olho: é dessa maneira que a parte branca de dentro do olho é destacada como um mármore luminoso e parece quase vir para fora dela, relativamente fora da "pele" da máscara.

Essas máscaras são cortadas logo abaixo do nariz e das bochechas, pois as personagens da Commedia dell' Arte, falam, e falam demais; logo a boca do ator deve estar livre para se mover. No momento em que a máscara encosta o rosto, a mudança da máscara de couro escura para a pele pálida subjacente ficaria muito evidente e destacada, então na área das maças do rosto, onde as mulheres costumavam usar sutilmente o ruge, ou onde os homens antigamente costumavam deixar crescer as costeletas, duas áreas são coloridas e matizadas com maquiagem marrom. Depois de ter maquiado esses quatro pontos sobre o rosto, se o ator mover a cabeça com movimentos exagerados que servem para trazer vida à máscara, você pode notar que a divisão entre o queixo e o pescoço não está mais claramente discernível à distância. Essa divisão é re-criada com a pintura de uma 'barbicha" típica: estamos falando de uma linha fina e escura que traça a extremidade do osso maxilar e do queixo, acentuando a parte inferior do rosto.

Como todas as máscaras têm origem baixa, no povo, diz-se que elas sempre têm as orelhas sujas e por isso também devem ser pintadas de marrom. Além disso, se não

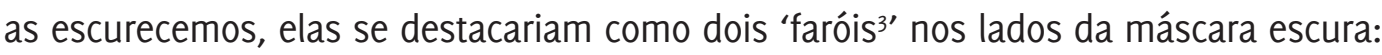
nós temos que subtrair o branco com maquiagem. No meio de muitos traços escuros no rosto, a boca parece quase desaparecer pelo fato de ser muita clara; ela também precisa ser redesenhada com maquiagem marrom a fim de fazê-la sobressair. 0 pescoço também deve ser realçado com cinco traços escuros característicos que enfatizam a estrutura e acentuam a força daqueles movimentos canhestros que servem para mover a máscara. Por fim, há um desenho muito particular a ser feito ao redor dos lábios e no queixo, o qual lembra aqueles títeres com cabeças de madeira que possuem uma boca que pode se mover pra cima e pra baixo com o intuito de falar.

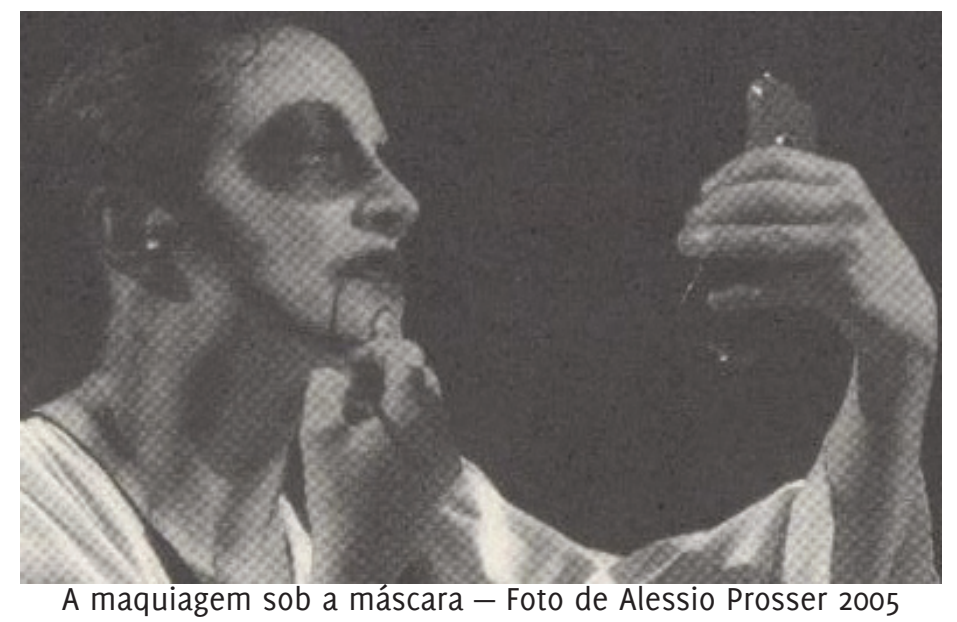

2 Light-beard.

3 Beacons. 

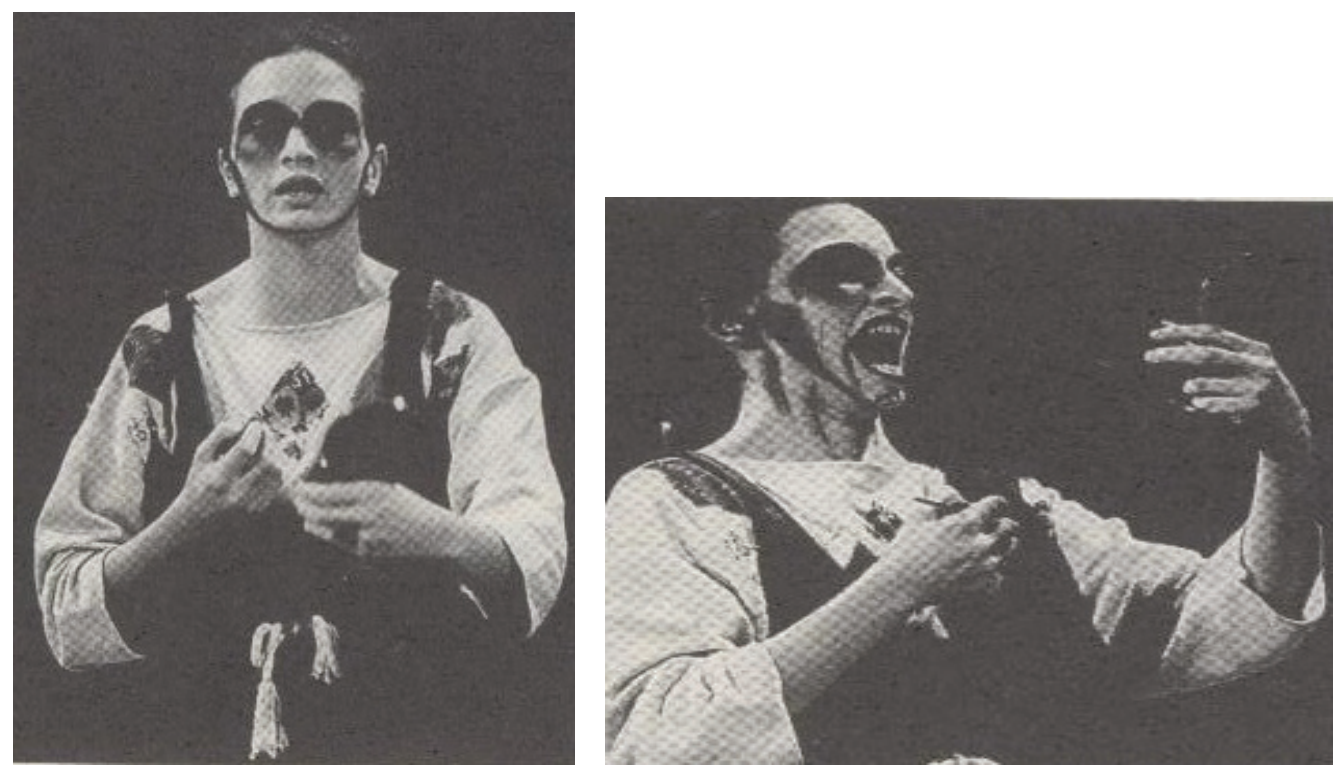

Demonstração da maquiagem sob a máscara - Foto de Pierluggi Rossoni 1994

E então, o mesmo tipo de desenho no rosto do ator é recriado de tal modo que a parte inferior, livre da máscara, também acaba sendo quase amadeirada e esculpi$\mathrm{da}$, acentuando os movimentos repentinos da mandíbula quando a boca se move para falar. Talvez este seja um dos aspectos mais bonitos do trabalho do ator: estar disponivel para rebocar-se como uma criança, mesmo na idade madura. A maquiagem sob a máscara já possui em si mesma uma alusão de 'mascaramento4' e de transformação grotesca das linhas do rosto.

Para as mãos, uma maquiagem especial também deve ser feita para que o seu tamanho e movimento tenham destaque: linhas escuras são matizadas no meio dos dedos em direção às costas das mãos. A coloração dos dedos sublinha a articulação dos dedos. Alguns matizes seguem os tendões do pulso até o antebraço, acentuando as tensões da musculatura em movimento quando há gesticulação. $\mathrm{Na}$ Commedia dell' Arte o trabalho com as mãos é muito importante, pois tudo aquilo que é verbalizado em palavras é também 'falado5' através da gesticulação. Esta maquiagem das mãos contribui para o 'desenho' de movimentos no espaço e se faz legível a uma grande distância, mesmo até a última fileira do teatro. Cada parte do corpo despida de qualquer figurino deveria ser adequadamente pintada. Se Arlecchino caminha descalço, mesmo os pés, tornozelos, canelas devem estar necessariamente 'sujas'?.

\footnotetext{
4 Masking.

5 Spoken.

6 Drawing.

7 Dirtied.
} 


\section{Cena Dezesseis - 0 Rosto sob a Máscara}

Neste momento o ator está pronto para finalmente colocar a máscara. Agora começa outra jornada de transformação. Pouco a pouco, a relação entre as linhas grotescas da máscara e os músculos faciais do ator ficará, com o treinamento, cada vez mais próxima, como se fosse algum tipo de colaboração simbiótica. É dito que um profissional da Commedia dell' Arte, com o passar do tempo e com estímulo frequente, começa, de alguma forma, a parecer com a sua própria máscara, como se houvesse uma leve adaptação das suas feições. Nós não deveríamos ficar muito surpresos com isso, pois mesmo nossos próprios pés se adaptam aos sapatos que usamos: o pé de uma menina que sempre usa sapatos de salto baixo é diferente de uma menina que sempre usa sapatinhos delicados de salto fino, e também é diferente de um pé esportivo que cresceu em sapatos de ginástica. 0 indubitável é que o rosto do ator, como todo o resto de seu corpo devem ter uma grande elasticidade e mobilidade a fim de ser capaz de se adaptar às deformações e aos movimentos que a máscara exige. Depois de tudo o que nós explicamos sobre o grande empenho físico que é exigido do ator da Commedia dell' Arte, seria equivocado pensar que o rosto que se esconde sob a máscara esteja imóvel e inerte: seria como dizer que o pé de um atleta, fechado dentro de um sapato esportivo altamente técnico, não trabalha durante a competição.

Observemos alguns exemplos de como o rosto trabalha, atuando sob a máscara. A máscara do Zanni, por exemplo, geralmente tem as sobrancelhas bastante arqueadas, um nariz proeminente e formas que se destacam um pouco em relação ao plano da face. Elas são alongadas, linhas extensas para que a parte inferior e descoberta do rosto se adapte à expressão particular da boca que, como vimos, identifica o estupor do Zanni.

( 0 ator coloca a máscara e executa uma breve improvisação, em silêncio, da personagem do Zanni; ele tira a máscara na frente dos espectadores, exibindo a deformidade assumida pelo rosto.)

Você notará um alongamento artificial dos lábios e um posicionamento da mandíbula superior que, após a abertura, quase se sobrepõe ao maxilar inferior ao nível da articulação, mas mesmo o resto do rosto, que não pode ser visto sob a máscara, reage com as características da máscara de couro; as sobrancelhas são arqueadas, os olhos bem abertos, numa geral deformação vertical do eixo da face.

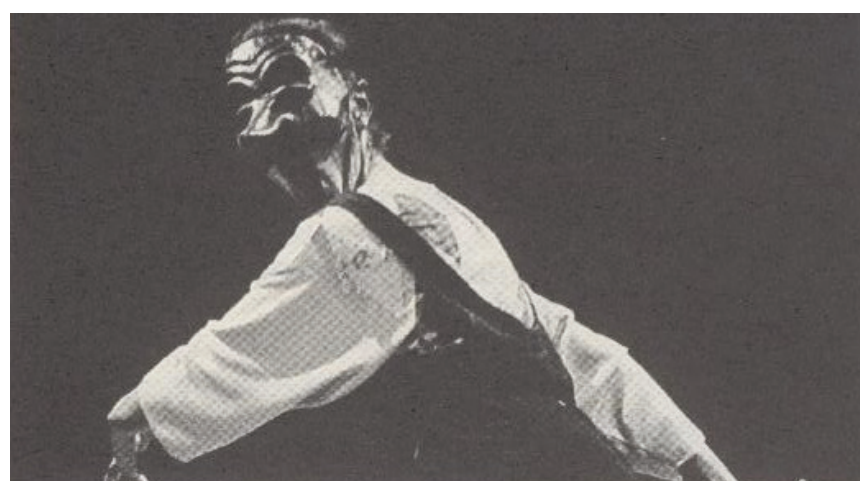

Uso da Máscara do Zanni (detalhe) - Foto de Pierluigi Rossoni 1994 


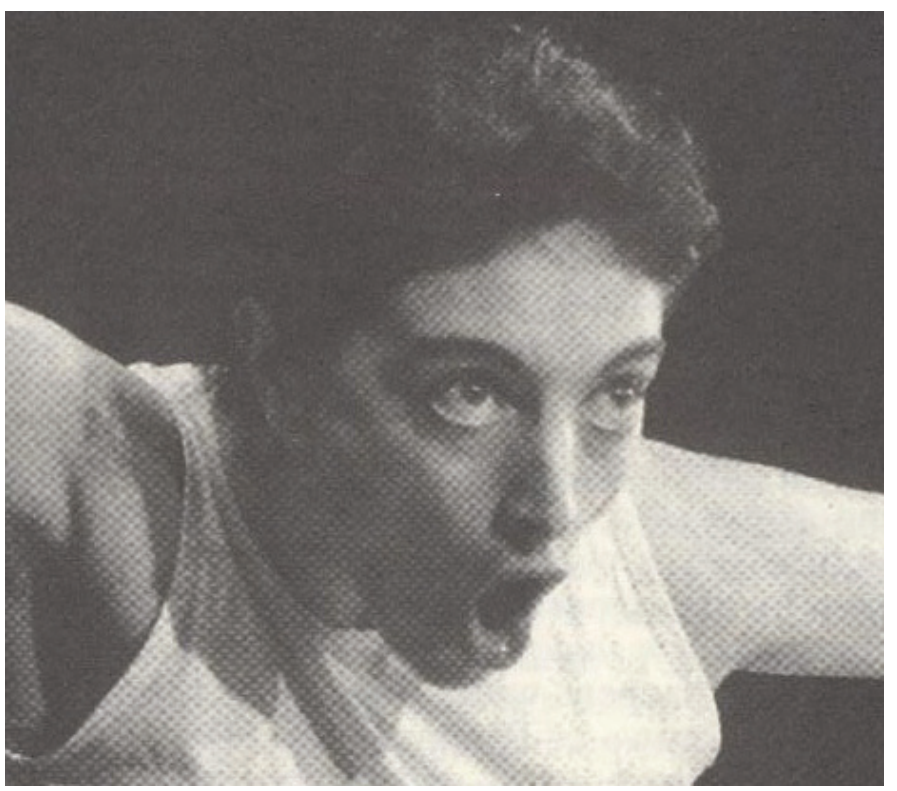

Deformação do rosto do ator sob a Máscara do Zanni (detalhe) - Foto de Daniele Cuidetti 1995

A máscara de Pantalone, ao contrário, possui um relevo intermediário e tem características onduladas voltadas para baixo: o nariz arrebitado tem um tipo de forma curva "elegante" como o do bico de um papagaio e as bochechas são caídas enquanto, ao invés disso, apenas a testa e as sobrancelhas são curvas e franzidas para cima. A parte inferior do rosto do ator também tem que ser 'ondulada'8 para completar o efeito da máscara.

( 0 ator coloca a máscara e executa, como antes, uma breve improvisação em silêncio; ele, então, tira a máscara, e exibe o rosto.)

Neste caso, você notará um alongamento do queixo parecido com o do macaco, uma compressão e afinamento da boca que é fechada e 'enrolada', com uma tensão sobre o lábio superior que quase faz o nariz torcer e, com o maxilar inferior projetado para frente que faz com que o interior do lábio inferior avolume-se como acontece com algumas bocas desdentadas. As típicas sobrancelhas de Pantalone são muito arqueadas, mas o olho não é amplamente aberto como no Zanni.

A máscara do Arlecchino tem as características mais largas e achatadas; mais encurtada verticalmente e mais extensa horizontalmente como acontece às vezes com as características de algumas máscaras dos mais antigos Zannis dos quais Arlecchino e Brighella se originam.

( 0 ator coloca a máscara e segue como anteriormente, até tirar a máscara e mostrar o rosto.)

8 curling

9 Curled/ondulada, torcida, enrolada. 
Mesmo a deformação correspondente do rosto é mais achatada: o extenso sorriso Arlecchinesco arreganhado $^{10}$ é ampliado lateralmente, quase como se quisesse arrebentar até as orelhas; as bochechas são 'franzidas"', as pálpebras inferiores são um pouco levantadas sob os olhos enquanto as superiores e os arcos das sobrancelhas são muito abertos e dilatados. A máscara esconde do público o rosto do ator, mas o trabalho que é desenvolvido pelo rosto sob a máscara é realmente muito maior do que aquele rosto exigido no teatro naturalista em que a máscara é desnecessária. Esse tipo de trabalho não é uma pretensão voluntária de expressões, é, na verdade, mais do que isso, um instinto bem treinado de reatividade pré-expressiva ligada às ações de todo o resto do corpo.

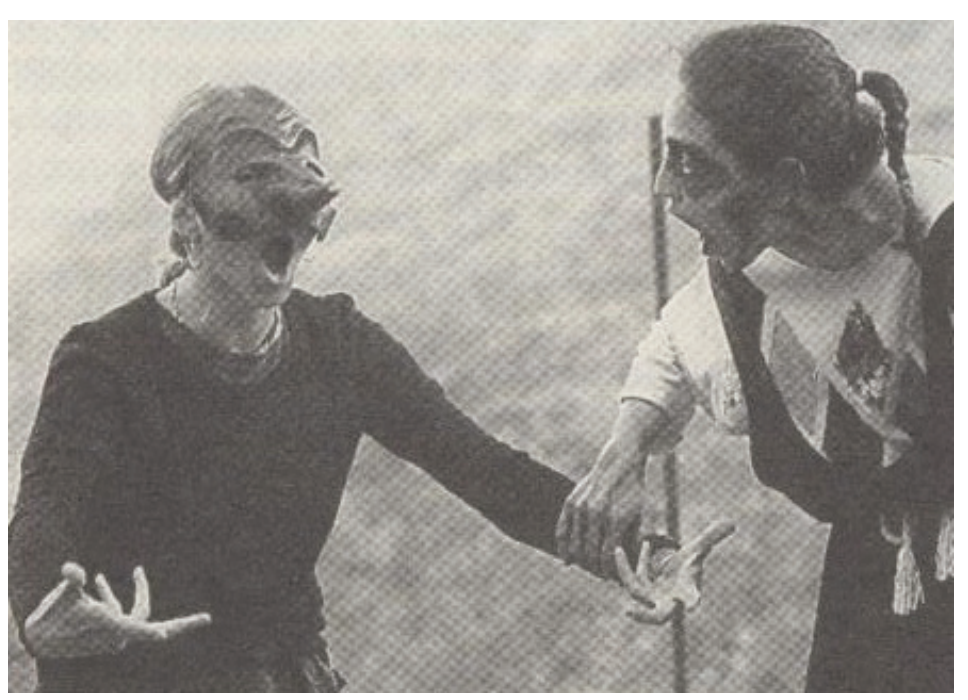

Uma estudante treinando as deformações sob a máscara de couro de um Zanni - Foto de Tony D ' Urso 1993

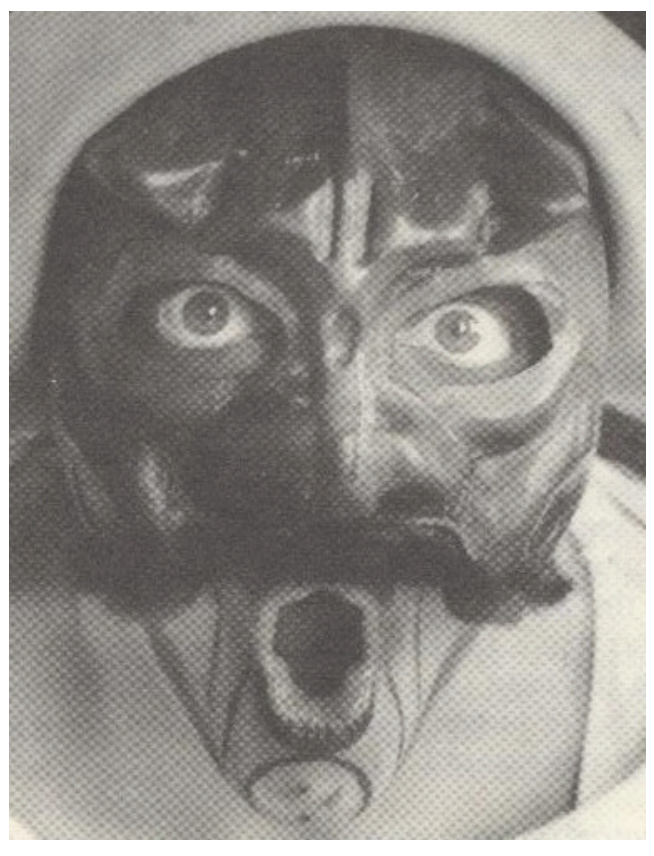

Retrato de Arlecchino - Foto de Héctor Gonzàlez 1999

10 Grinning smile.

11 Ruffled. 


\section{Referências}

> CONTIN, Claudia. Gli Abitanti di Arlecchinia. Favole didatiche sull' Arte dell' Attore. Campanotto Editore. 1999. $2^{\mathrm{a}}$ edição - 2006.

Claudia Contin é especializada em mimo e dialética corpórea. Conhecida no mundo como a única mulher Arlecchino. Publicou vários livros sobre técnica teatral, entre os quais se destacam Viaggio di um attore nella Commedia dell' Arte e Cli Abitanti di Arlechinia do qual a tradutora extraiu dois dos vinte capítulos. Também é fundadora, com Ferrucio Merisi, da Scuola Sperimentale dell’ Attore em Pordenone (Itália).

Aline Castaman, Programa de Pós-graduação em Artes Cênicas - PPGAC/UFRGS, linha de pesquisa 2 - Linguagem, Recepção e Conhecimento em Artes Cênicas. alinecastaman@gmail.com 